\title{
Os saberes das Redes de Economia Popular Solidária do Extremo Sul do Brasil: análise do município de Jaguarão, RS
}

\author{
Los saberes de las Redes de Economía Popular Solidaria del Extremo Sur \\ de Brasil: análisis del municipio de Jaguarão, $R S$ \\ The knowledge of the Networks of Solidary Popular Economy of the \\ Extreme South of Brazil: analysis of the municipality of Jaguarão, $R S$
}

Vitor Garcia Stoll ${ }^{1}$

Simone Silva Alves ${ }^{2}$

\begin{abstract}
Resumo
Este trabalho apresenta um recorte do Projeto de Extensão Universitária "Os saberes das Redes de Colaboração Solidária da Fronteira do Extremo Sul do Brasil", vinculado a Universidade Federal do Pampa, Campus Jaguarão. Entende-se a Economia Popular Solidária (EPS) como uma proposta econômico-política que busca através de um conjunto de ações recuperar não só o sentido social e ético da economia, mas enfrentar a desigualdade, a pobreza e a exclusão social. Objetivou-se conhecer e mapear os grupos que compõem as Redes de Colaboração Solidária de Jaguarão/RS. A pesquisa é de caráter qualitativo, guiada na perspectiva Marxiana, sendo a coleta de dados realizada através de observação participante e entrevista semiestruturada aplicada aos sujeitos que participam da Casa, Fórum e Feira da EPS. Mapeou-se que no município há um total de 81 Empreendimentos Econômicos Solidários, atuando em diferentes áreas de produção. Os sujeitos entendem a EPS como uma maneira justa de comércio (32\%), um trabalho coletivo (49\%) norteado por saberes populares (19\%). Um dos desafios dos grupos da EPS em Jaguarão é obter um espaço no Mercado Público, pois até o momento ainda não foi acordado com a Gestão Pública. Concluiu-se que os sujeitos criam redes de estratégia para potencializar as conexões já existentes com outros empreendimentos solidários, buscando um movimento de crescimento conjunto, autossustentável e antagônico ao capitalismo.
\end{abstract}

Palavras-Chave: Desigualdades Socioeconômicas; Economia Popular Solidária; Saberes Populares; Sororidade; Trabalho Coletivo.

\section{Resumen}

Este trabajo presenta un recorte del Proyecto de Extensión Universitaria "Los saberes de las Redes de Colaboración Solidaria de la Frontera del Extremo Sur de Brasil", vinculado a la Universidad Federal de Pampa, Campus Jaguarão. Se entiende la Economía Popular Solidaria (EPS) como una propuesta económico-política que busca a través de un conjunto de acciones recuperar no sólo el sentido social y ético de la economía, sino enfrentar la desigualdad, la pobreza y la exclusión social. Se objetivó conocer y mapear los grupos que componen las Redes de Colaboración Solidaria de Jaguarão / RS. La investigación es de carácter cualitativo, guiada en la perspectiva Marxiana, siendo la recolección de datos realizada a través de observación participante y entrevista semiestructurada aplicada a los sujetos que participan en la Casa, Foro y Feria de la EPS. Se ha mapeado que en el municipio hay un total de 81 Emprendimientos Económicos Solidarios, actuando en diferentes áreas de producción. Los sujetos entienden la EPS como una manera justa de comercio (32\%), un trabajo colectivo (49\%) orientado por saberes populares (19\%). Uno de los desafíos de los grupos de la EPS en Jaguarão es obtener un espacio en el Mercado Público, pues hasta el momento aún no se ha acordado con la Gestión Pública. Se concluyó que los sujetos crean redes de estrategia para potenciar las conexiones ya

${ }^{1}$ Licenciado em Ciências da Natureza; Universidade Federal do Pampa; Bagé, Rio Grande do Sul, Brasil; vitorgarciastoll@gmail.com

${ }^{2}$ Doutora em Educação; Universidade Federal do Pampa; Jaguarão, Rio Grande do Sul Brasil; sialves554@gmail.com 
existentes con otros emprendimientos solidarios, buscando un movimiento de crecimiento conjunto, autosostenible y antagónico al capitalismo.

Palabras claves: Desigualdades Socieconómicas; Economía Popular Solidaria; Saberes Populares; Sororidad; Trabajo Colectivo.

\begin{abstract}
This work presents a cut of the Project of University Extension "The Knowledge of Networks of Solidary Collaboration of the Border of the Extreme South of Brazil", linked to the Federal University of Pampa, Jaguarão Campus. The Popular Solidarity Economy (EPS) is understood as an economic-political proposal that seeks through a set of actions to recover not only the social and ethical sense of the economy, but to face inequality, poverty and social exclusion. The objective was to know and map the groups that make up the Solidary Collaboration Networks of Jaguarão / RS. The research is qualitative, guided in the Marxian perspective, and the data collection is done through participant observation and semi-structured interview applied to the subjects that participate in the House, Forum and Fair of EPS. It was mapped out that in the municipality there are a total of 81 Economic Solidarity Projects, working in different production areas. The subjects understand the EPS as a fair way of commerce (32\%), a collective work (49\%) guided by popular knowledge (19\%). One of the challenges of the EPS groups in Jaguarão is to obtain a space in the Public Market, as it has not yet been agreed with Public Management. It was concluded that the subjects create networks of strategy to potentiate existing connections with other solidarity enterprises, seeking a joint growth movement, self-sustaining and antagonistic to capitalism.
\end{abstract}

Keywords: Collective Work; Popular Knowledge; Popular Solidarity Economy; Socioeconomic Inequalities; Sorority.

\title{
1. Introdução
}

O capitalismo tem dominado grande parte das sociedades contemporâneas. A mercantilização é uma das bases essenciais desse sistema de produção, pois o que tem valor são a mercadoria e o lucro. Ou seja, a mercantilização da educação, das relações sociais, da cultura, da saúde, da política, dos homens e das mulheres, enfim da vida. Com efeito, a desigualdade social é o que impera com força total nesse modo de produção da riqueza hegemônico.

Contrária às bases do capitalismo surgem na década de 1980 algumas práticas de Economia Popular Solidária no Brasil. Essas ações ganharam força na década de 1990, com a organização dos trabalhadores através das associações, programas, agências de desenvolvimento, dentre outras. No entanto, só a partir do governo Lula no ano de 2003, a Economia Popular Solidária (EPS) teve consolidada sua institucionalização no país (SILVA 2015; ROSA, 2013). Conforme Singer (2002, p. 10) “a Economia Solidária é outro modo de produção, cujos princípios básicos são a propriedade coletiva ou associada do capital e o direito à liberdade individual”.

A EPS é uma corrente de pensamentos e de ações que busca, de maneira coletiva e criativa, superar o severo sistema de produção capitalista, através dos princípios da autogestão, cooperação, reciprocidade, solidariedade e bem-comum. Ela é constituída por 
grupos de trabalhadores e trabalhadoras que desenvolvem, de maneira coletiva, atividades de produção e/ou prestação de serviços através de associações comunitárias, cooperativas populares, feiras de cooperativismo, dentre outras.

Atualmente a EPS tem ganhado espaço entre as diferentes culturas, setores e áreas do Brasil. No que tange a faixa de fronteira com o Uruguai, o Rio Grande do Sul apresenta um cenário ainda em construção no que se refere ao propósito de fazer Economia Solidária. Esse espaço merece um olhar atento da sociedade e governança em geral, trata-se de uma área populosa que há muito tempo enfrenta inúmeros desafios na busca pelo desenvolvimento regional. Fatores como: infraestrutura insuficiente, precariedade do setor de transporte, déficit de empregabilidade, falta de ações de empreendedorismo social e formação pessoal, muitas vezes, comprometem o progresso econômico dessa região. Contudo, as populações fronteiriças têm buscado práticas alternativas de economia, oportunizadas pelo deslocamento de pessoas entre os dois países. São cidadãos que por algum motivo não estão inseridos no mercado de trabalho e/ou necessitam complementar a renda mensal de sua família, e para isso recorrem às atividades de autogestão.

Considerando a relevância em conhecer e compreender melhor o cenário da EPS realizada na área de fronteira foi criado projeto de extensão universitária "Os Saberes das Redes de Colaboração Solidária do Extremo Sul do Brasil” vinculado à Universidade Federal do Pampa - UNIPAMPA - Campus Jaguarão/RS. Esse projeto busca servir como condutor das distantes realidades sociais e demandas de setores diversos que compõem a complexa rede de problemas educacionais, econômicos, culturais e políticos. A noção de Rede de Colaboração Solidária resulta da reflexão sobre práticas de atores sociais, compreendidas sob a ótica da teoria da complexidade e da filosofia da libertação. Enquanto categoria analítica denota a existência de conexões entre os empreendimentos e iniciativas de economia solidária e a circulação colaborativa entre eles de informação, valores e materiais. Seus fluxos podem ser realimentados de maneira centralizada, descentralizada ou distribuída, embora sua formação seja sempre complexa, realimentando simultaneamente fluxos de diversos tipos.

Neste sentido, entende-se que esse diálogo crítico com as problemáticas sociais pode reconectar as universidades para o desafio de um olhar e de um fazer cada vez mais necessário no combate às desigualdades econômicas, sociais, raciais e étnicas em nosso país. Neste artigo apresenta-se um recorte das ações desenvolvidas, na qual, objetivou-se conhecer e mapear os grupos que compõem as Redes de Colaboração Solidária do município de Jaguarão/RS. 


\section{Caminhos da pesquisa}

Metodologicamente essa investigação caracterizou-se como qualitativa, pois, levaramse em consideração as características dos grupos que compõem as redes de EPS, preocupando-se não apenas contabilizar os resultados, mas em tentar entender o porquê de ter obtido determinada constatação (TRIVIÑOS, 2007). De acordo com Gil (2002, p. 133), esse tipo de investigação define-se como “(...) uma sequência de atividades, que envolve a redução dos dados, a categorização desses dados, sua interpretação e a redação do relatório", podendo variar de acordo com a extensão da amostra, instrumentos de pesquisa e pressupostos teóricos.

A coleta de dados foi realizada, no ano de 2017, através de observação participante e entrevista semiestruturada, aplicada aos sujeitos que participam da Casa, Fórum e Feira de EPS de Jaguarão, RS. Os dados empíricos foram transcritos numa planilha sendo analisados a partir de duas categorias:

Cadeia de produção: apresenta os produtos comercializados, local de comercialização, meio de divulgação dos produtos e também as demandas dos empreendedores sociais.

Concepções sobre a EPS: descreve a concepção dos sujeitos da pesquisa sobre a Economia Popular Solidária.

\section{Resultados e discussões}

Na categoria cadeia de produção mapeou-se que na cidade de Jaguarão há um total de 81 Empreendimentos Econômicos Solidários (EES). O Gráfico 01 apresenta a distribuição desses empreendimentos por cadeia de produção.

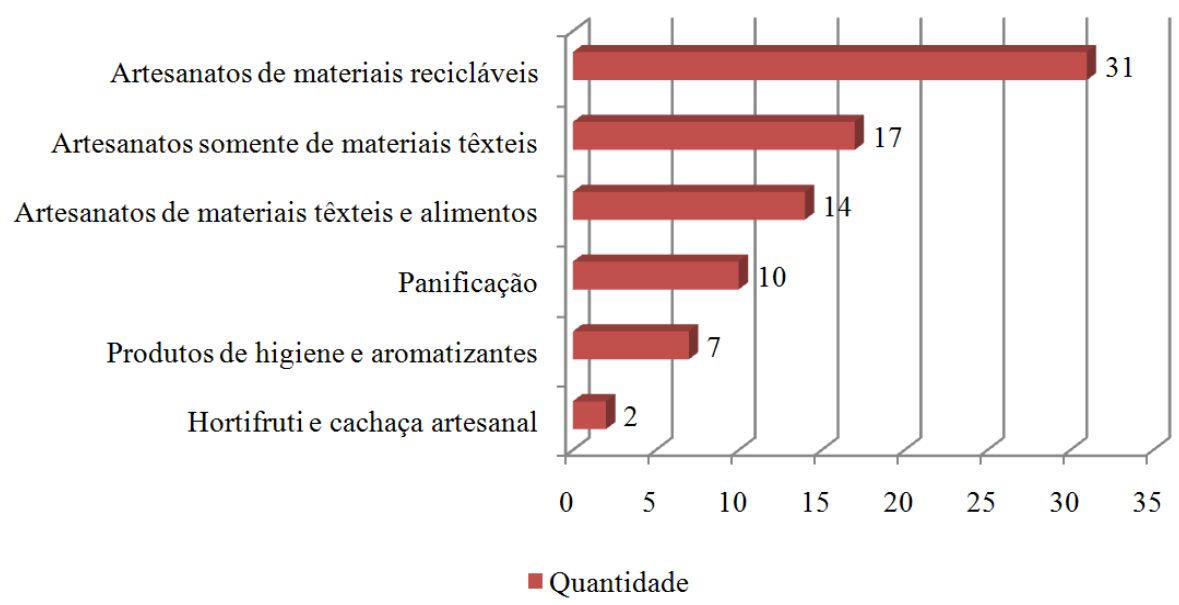

Figura 1 - Categorização dos produtos comercializados pelos EES de Jaguarão, RS.

Fonte: Stoll e outros (2017). 
Constatou-se que a maioria dos produtos comercializados são confeccionados por artesões e artesãs. Em 31 dos EES (38,5\%) os artesanatos são feitos com materiais recicláveis, como garrafas plásticas, vidros, papeis, dentre outros; 17 dos EES (21\%) confeccionam artesanato com materiais têxteis; e 14 (17\%) além de artesanato, comercializam também produtos alimentícios. Os demais empreendimentos caracterizam-se pela produção e venda de pães e bolos (12\%); produtos de higiene e aromatizantes (9\%); e hortifruti e cachaça artesanal $(2,5 \%)$.

No que tange ao local de comercialização $97,5 \%$ concentram-se na zona urbana atuando principalmente na Casa e na Feira de Economia Solidária. Dois empreendimentos $(2,5 \%)$ atuam também na zona rural. Todos os pesquisados $(100 \%)$ afirmaram fazer a divulgação de seus trabalhos através de conversas informais e 74\% utilizam também páginas nas redes sociais. Apesar de não ter sido citada, também há divulgação na rádio comunitária local.

Como desafio, uma das principais lutas dos grupos da EPS no município de Jaguarão é obter um espaço gratuito no Mercado Público, pois diferentemente das organizações de economia mercantil tradicional, não possuem como foco a busca pelo lucro, base do capitalismo. Conforme corrobora França Filho (2004), os EES almejam objetivos além dos aspectos econômicos, visando um equilíbrio entre os fatores sociais, políticos, culturais e ambientais, ou seja, neste modelo de economia não há concorrência, há coletividade. Tal constatação evidencia-se na pesquisa, pois todos os sujeitos afirmaram não considerar como concorrente uma pessoa que faz o mesmo trabalho, pois entendem que um depende do outro para se consolidarem enquanto empreendedores da EPS.

Ao analisar a categoria concepção sobre a EPS constatou-se que $49 \%$ percebem-na como trabalho coletivo, $32 \%$ como comércio justo e $19 \%$ como saberes populares. Os sujeitos entendem que a EPS é uma maneira justa de comércio, um trabalho coletivo onde não existe exploração do trabalhador. É um ato social, educativo e de troca com o objetivo de ajudar o próximo.

Neste sentido, percebeu-se que EPS surge como um instrumento de defesa da classe trabalhadora usando de mecanismos para combater as novas transformações do mundo do trabalho e a nova proposta capitalista que tem como característica principal o desemprego estrutural e a desvalorização do trabalho coletivo (SINGER, 2004). Constatou-se que a maioria dos sujeitos são mulheres, que se inseriram nas redes de Economia Solidária da cidade de Jaguarão por estarem desempregadas, atuando, muitas vezes, informalmente. 
Para Singer (2004, p. 11), “[...] o que importa entender é que a desigualdade não é natural e a competição generalizada tampouco o é”. Ou seja, a presença quase que unânime de mulheres na EPS é reflexo de uma sociedade em que ainda impera o patriarcado, e que precisa ser reconstruída urgentemente através da sororidade. Entende-se que a sororidade conduz a emancipação de cada mulher que se percebe como sujeito social capaz de decidir de forma autônoma e singular, caracterizando-se numa perspectiva integradora e de uma aprendizagem multidimensional da construção coletiva dos saberes das mulheres, tendo como fim a formação de sujeitos ativos e conscientes da realidade em que estão inseridos.

Conforme destaca Alves (2014), na Economia Solidária, os modos e as formas dos saberes do trabalho se efetuam no grupo, na troca de experiências, no diálogo e nas discussões que o outro traz e compartilha no coletivo. De acordo com os sujeitos pesquisados, os saberes construídos por eles foram passados ao longo das gerações e construídos coletivamente com o grande grupo. Percebe-se, portanto, a presença de mulheres veteranas na EPS. Para a autora, o termo "veterana" na EPS não está relacionado somente à idade, mas sim, a experiência de trabalho. Ressalta-se que gênero é uma relevante categoria de análise social. Pois a guisa desse projeto se baseia no conceito de gênero abordando a divisão social do trabalho como núcleo central da desigualdade entre homens e mulheres. Nesse sentido, as desigualdades de gênero e a invisibilidade da mulher que perpassam a sociedade capitalista ainda encontram-se vigorosas em pleno século XXI.

Por fim, compreende-se que esses dados demonstram a necessidade e o potencial de articulação entre as políticas públicas de promoção da Economia Solidária e as políticas de educação, especialmente a Educação de Jovens e Adultos (EJA). Nessa visão é possível perceber que a educação não formal e a EJA buscam capacitar às pessoas para se tornarem cidadãos "do" e "no" mundo.

É preciso frisar a importância de levar a sério a necessidade do envolvimento da educação com as desiguais relações de poder para não haja distanciamento do mundo real. Conforme estudos realizados, percebe-se que a educação está imersa nos processos culturais e que não é possível conceber uma experiência pedagógica desvinculada das questões culturais da sociedade. (CANDAU, 2011).

Entende-se que essa educação busca amenizar as grandes modificações no campo econômico, na economia e no mundo do trabalho. Com o objetivo de melhorar o nível de qualidade de vida das pessoas que vivem excluídas na sociedade, a EJA pode proporcionar a estes trabalhadores e trabalhadoras esperança e expectativa de melhora de vida. Num sentido mais amplo, as especificidades da educação são várias. Dentre elas está à educação não 
formal, uma modalidade que tem ocupado um espaço importante no cenário brasileiro e que, por isso, vem fazer jus a distintos segmentos da sociedade.

\section{Considerações finais}

Salienta-se que as redes de EPS são um espaço rico em diversidade de saberes, produzidos por diferentes atores sociais, que na maioria das vezes não são reconhecidos. Através dos projetos constatou-se que os sujeitos criam redes de estratégia para potencializar as conexões já existentes com outros empreendimentos solidários, buscando um movimento de crescimento conjunto, autossustentável e antagônico ao capitalismo.

Neste sentido, a EPS na sua pluralidade está constituída por grupos, associações, formas de produzir e consumir que ressignificam às práticas de solidariedade, sejam elas novas ou antigas. Suas práticas vão à contramão do modo hegemônico de produzir riqueza e dividir os bens em sociedade, na medida em que mantêm intensa relação com aspectos locais da cultura, do ambiente, dos arranjos sociais, educacionais e políticos.

De acordo com Laville e Gaiger (2009, p. 166) “o agir coletivo da economia solidária, consubstanciado na autogestão, institui nos protagonistas no mundo de trabalho e nos embates da cidadania, em resposta a anseios de bem-estar, reconhecimento e vida significativa". Por isso, as estratégias de educação e atuação políticas se apresentam diferenciadas, na medida em que outras balizam o seu agir: autogestão, protagonismo, reconhecimento e valorização dos saberes da comunidade. Economia Solidária ao atuar como contraponto aos efeitos perversos da organização neoliberal abre possibilidades de vigilância política, construção de outras sociabilidades que vão além da produção da riqueza. As questões que este trabalho traz estão diretamente relacionadas ao pensar esta outra sociabilidade cuja essência está além da organização de postos de trabalho, renda e lucro.

Portanto, assumir uma concepção ampliada de educação, escolar ou não, antes de tudo, é romper com as concepções e práticas educativas limitadas às exigências de um mercado, é distanciar-se e contrapor-se às restrições impostas pelo sistema capitalista o qual não economiza força para apartar a compreensão da educação. (FREIRE, 1980; MÉSZÁROS, 2009). Por fim, repensar a economia da produção de riqueza, de forma crítica é tarefa necessária para educadores e cientistas sociais.

\section{Referências}

ALVES, S. S. Saberes das Mulheres Veteranas na Economia Solidária: Sororidade a Outra Educação! 2014. 173 f. Tese (Doutorado em Educação) - Programa de Pós-Graduação em 
Educação, Faculdade de Educação, Universidade Federal do Rio Grande do Sul, Porto Alegre, 2014.

CANDAU, V. M. F. Diferenças culturais, cotidiano escolar e práticas pedagógicas. Currículo sem Fronteiras, v.11, n.2, p. 240-255, jul/dez. 2011. ISSN 1645-1384. Disponível em: http://www.curriculosemfronteiras.org/voll1iss2articles/candau.pdf. Acesso em: 06 jan. 2018 .

FRANÇA FILHO, G. C de. Economia Solidária: uma abordagem internacional. Porto Alegre: editora da UFRGS, 2004.

FREIRE, P. Conscientização: teoria e prática da libertação: uma introdução ao pensamento de Paulo Freire. São Paulo: Moraes, 1980.

GIL, A. C. Como elaborar projetos de pesquisa. 4. ed. São Paulo: Atlas, 2002.

LAVILLE, J. L.; GAIGER, L. I. G. Economia Solidária. In: HESPANHA, P. Dicionário Internacional da Outra Economia. Coimbra: Almedina, 2009, p. 162-168.

MÉSZÁROS, I. A Educação Para Além do Capital. São Paulo: Boitempo Editorial, 2009.

ROSA E. P. Políticas Públicas de Economia Solidária no Rio Grande do Sul. 2013. 148 f. Dissertação (Mestrado em Sociologia) - Programa de Pós-Graduação em Sociologia, Instituto de Filosofia e Ciências Humanas, Universidade Federal do Rio Grande do Sul, Porto Alegre, 2013.

SILVA, S. L. de P. Histórico da Economia Solidária No Brasil. In: CONGRESSO DE PESQUISADORES DE ECONOMIA SOLIDÁRIAM, 1, 2015, São Carlos. Anais... São Carlos, 2015. Disponível em: http://www.conpes.ufscar.br/wpcontent/uploads/trabalhos/gt5/sessao-3/silva_sidlia.pdf. Acesso em: 06 jan. 2019.

SINGER, P. Um olhar diferente sobre a Economia Solidária. In: FRANÇA FILHO, G. C. de; LAVILLE, J. L. Economia Solidária: uma abordagem internacional. Porto Alegre: editora da Universidade Federal do Rio Grande do Sul, 2004, p. 6-11.

SINGER, P. Introdução à Economia Solidária. São Paulo: Editora Fundação Perseu Abramo, 2002.

STOLL, V. G; ALVES, S. S.; DIAS, P. H. V.; ZDRADEK, R. Economia Popular Solidária: Desafios e Possibilidades. In: SALÃO INTERNACIONAL DE ENSINO, PESQUISA E EXTENSÃO, 9, 2017, Santana do Livramento. Anais... Santana do Livramento, 2017. Disponível em: http://seer.unipampa.edu.br/index.php/siepe/article/view/31199/16702. Acesso em: 08 jan. 2019.

TRIVIÑOS, A. N. da S. Introdução à Pesquisa em Ciências Sociais: a pesquisa qualitativa em educação: o positivismo, a fenomenologia, o marxismo. São Paulo: Atlas, 2007. 